relative level of land and sea. They must have been formed when the land was higher than it is at present,-perhaps not more than 200 feet. These submarine peat-bogs may have been formed contemporaneously with the shell-deposit next noticed.

Some years ago, when dredging on the west side of the Dogger Bank, off the coast of Durham, in about 50 fathoms water, the dredge brought up a large quantity of dead specimens, in a chalky condition, of Mya truncata (Annals Nat. Hist. vol. xviii. p. 233). It is impossible to conceive that these specimens of a iittoral species lived at the deptb from which they were procured; wor can 1 admit that they have been transported from a shallower habitat by marine currents. There is less difficulty in contending that they lived on the spot which yielded them, when the Dogger Bank was a subaerial surface; and that the species ceased to live in the locality when the land became submerged.

Third epoch.-Influenced by the investigations of Geikie, also by some considerations given in a notice which I have elsewhere published ('Parthenon,' No. 50, April 11, p. 417), I am led to believe that the "Glasgow canoe-sands" are not so ancient as some archæologists have conceived. Possibly some portion of this deposit may be of high prehistoric antiquity ; but evidently some of it was formed when Scotland was occupied by the Romans.

Admitting the view just stated to be correct, it necessarily follows that the geological epoch under consideration includes the historical era of our country. A question now suggests itself-A re the slight vertical movements of the Post-Glacial period equal in chronological value to the much larger ones of the Glacial period? Or anotherAre they simply equivalents of the minor oscillations which accompanied the great movements of the latter term? Considering the magnitude of the physico-geographical changes which characterized the Glacial period, as compared with those of the following one, I feel most inclined to adopt the view comprehended in the last question. In this case it may be contended that the Post-Glacial period has not yet advanced beyond its initial stages.

\title{
SPECULATIONS ON POSSIBLE PHYSICAL AND COS- MICAL PHENOMENA IN REFERENCE TO THE PAST CONDITIONS OF OUR EARTH.
}

By S. J. MACKIE, F.G.S.

Whenever we begin to think about the formation of the universe we get at once into the realms of speculation, and the only value of our thoughts rests in their probability. In everything unknown we must first form an idea-that is, speculate ; then, by partial gatherings of facts, or by positive reasoning, we may theorize. Ultimately, by the accumulation of evidence, we may prove that which, in the 
first place, we only imagined. When first men observed the sun, they regarded the earth as a flat plain, over which the sun passed in his heavenly course, and below which, at eve, he retired to rest. It was not until many ages had elapsed that the world came to be regarded as round, and even then it was long before the sun was considered as a fixed centre of the planetary system revolving round him.

By no nation of ancient times has astronomy been more advanced than the Greeks. Not that the Greeks ever worked out much to a proved result, but they were an imaginative people, and they invented notions. If one theory or speculation was disproved, they invented another; and, hit or miss, they always seemed to have fresh ideas in reserve. In some things astronomical, as in many other things that the world believes in, we may be heretics, and we admit we do not adhere to all the cosmical, physical, geological, and spiritual tenets of the popular faiths. We may not entirely believe in the perfect stability of the universe; we may doubt the eternal endurance of the sun's bright rays; and we may not quite acquiesce in the unchangeable permanence of the planetary orbits : in short, we do not believe in the permanence of anything whatever in creation. All ever has been change, and changeful all things ever will be. Diversity and change are visible in the first created things of which any relics have been left us. Diversity and change are palpable in every living creature and every inanimate thing around. The foreshadowings of future changes fall everywhere and on everything. Never, in all the Great Past, do we find a ledge of stability on which to rest the mind's weary flight; nor in all the future can we spy one solitary changeless rock on which to seek repose. The mind, like the fabled flight of the gorgeous birds of paradise, is doomed to endless effort,-from birth to death to be ceaselessly on the wing. It is a fashion, however,-and has been more so than it is now, - to talk about the stability of the universe. Nothing is, ever was, or ever will be, fixed in space. Not even the "fixed" stars, for we know they are all in motion; and the spectral analysis of the light of some, at any rate, shows that those whose rays we can analyse are in a state of combustion-burning like our own sun. Notwithstanding the sublime edict for the creation of light in that Bible most people profess to believe, we suspect strongly that most people regard the light of our sun as eternal. If eternal in the future, why not eternal in the Past? If not eternal in the past, why eternal in the Future? Not that we think such arguments always bear.

The mind naturally clings to the idea that creation began; and the more educated, the more competent, the more reflective the mind becomes, the more it clings to the conviction that creation did begin. But having begun, having progressed, still progressing, who will dare to think it shall ever cease? Such a thought involves the extinction, death of the Creator. Never! More glorious and more powerful day by day, and age by age, the Almighty Strength may grow and increase, but diminish, cease,--never! But, back to our point. Has 
the sun shone for ever in the backward Past? Certainly not! Will it light up for ever in the endless future the vast and glorious space its beams illumine now? Perhaps not. The sun may go out-it may be millions of years to come ere it does, but its light may some day be darkened. It is a long time to look forward to when that will happen, we admit, and the race of mau may pass away like the many life-races of the Past, long before the bright rays of that "glorious orb" begin to fade. But change is evcrywhere; we see it in everything around us; we read the record of change everywhere and on everything in the Past. The first land, so far as we can make out, differed from our dry land now; the first plants differed from those that clothe the dry land now ; the first living creatures differed from the animated beings around us. Fish, flesh, nor fowl put on the same bodies; perhaps even air and ocean differ. How, then, were the planets weighed to a grain and forbidden to increase? Were their distances measured off to a millimetre, and the irrevocable order passed, "Nearer shalt thou not approach, further shalt thou not recede from the burning sun"? For the sun was the edict passed, "Without increase or waste, burning shalt thou go on for ever and ever"? Such an edict would make the sun an eternal creator of force. And no one believes in creation except from God. Who but $\mathrm{He}$, in the incomprehensible beginning of all things, created the first atom of force, and has gone on unceasingly multiplying force upon force ever since?

It is well even in this world now and then to go out of the beaten paths and to explore new lands-if even the result be only to convince us of the value of the old ones. It is well, too, in science now and then to diverge on to the realms of speculation-if even only to attain a conviction of the aceuracy of that which has been accepted. At one time we had too much of speculation and too little of facts, but in the advancing sciences of late, perhaps we have had too many facts and too few speculations. Bricklayers would make of bricks but a poor edifice if the architect had not imagined the building beforehand. We all know how Physical Geology, as a science, is looked at in the ordinary way; and no one who looks closely at the picture presented for our acceptance as the portraiture of what was, what has been, and what has happened, but must think that the picture offered has many flaws. The artists claim pre-Raphaelite minuteness and correctness in its execution; they profess to have studied facts, and to have built their picture up scene by scene, leaf by leaf, texture for texture. We do not condemn their preRaphaelite painting; but we claim the artist's right to let our fancy loose, and to sketch out imaginary pictures of our own.

Let those who have gone before us claim veracity for their depictions, we ask only that ours may be looked upon as fanciful scenes; but if in our visionary sketehings the tracery of truthful expression be detected, do us then the justice to let that be treasured and preserved. Our task is not to upset an old school and found a new, but to seek out 'lruth. 
For this purpose, then, we commence in this article a series of speculations on possible physical and cosmical phenomena in reference to the past conditions of our Earth, not always with the intention of proposing new views or even our own opinions, but as often putting hypothetical cases to learn what would have been the results produced by particular conditions of physical forces and the exertion in particular directions of cosmical laws.

At this lovely spring-time of the year, the bright warm beams of the shining sun cause our eyes to rise to the blue and cloud-mottled sky. All around, the green buds are shooting forth, and flowers blossoming and perfuming the balmy air. What would this beautiful world be without that sunshine?" What would indefatigable, active man be without these cheering, life-exciting beams of the orb of day? The sun is but a great fire; fire, we know, consumes the substances it feeds upon; gigantic as the solar orb may be, the fire must burn it out, and, like the dark stars that astronomers now have indicated, the time may come when the earth, changed, perhaps, itself to a burning mass, may reveal by its luminous beams to the astronomers of distant worlds its revolutions round an unseen, dark, extinguished sun. But without so deep a dive into the mysteries of time to come, let us ask ourselves what would be the effect of minor alterations in the solar fire? We cannot believe the solar flames are always burning at exactly the same height, with exactly the same fierceness, giving exactly the same heat, exactly the same light. The fire on our hearth flickers, blazes, grows dull, requires fresh fuel, smoulders, bursts into flame again, burns clear and ruddy, glows with radiant heat, darkens, chinkles, and goes out. The consumption of the solar fire must be supplied; we cannot believe that as particle by particle is consumed, particle by particle is supplied. Even if meteors supply the sun, they must vary in abundance at different periods of time. If worlds fall in occasionaliy to supply the waste, the solar fires at that spot must slackes, denden, to glow out again bright and more furiously when the new fuel is ignited through. For geological purposes, without going into great variations of the solur fire, let us corceive two modifications, - one of $15^{\circ}$ increase of temperature from such a cause, and one of $15^{\circ}$ decrease. We are told the centre of the earth is a burning incandescent fluid mass,-rather an uncomfortable idea, and not quite intelligible. We are taught it, however, mainly because the fossil relics of tormer creatures and plants are supposed to indicate tropical conditions in latitudes where now temperate conditions prevail. Unfortunately, however, in digging down into the bowels of the earth we do not find the temperature increase more and more with the depth, the heat increase faster and faster as we get nearer and nearer to this imaginary central melting-pot; we do not, in short, find the heat of the handle increase more rapidly as we pass from the knob to the red-hot end of the poker. Just as Glaisher going up in the high regions of the air has disproved the old doctrine of a supposed decrease of one degree of heat for every 300 feet of vertical height, and found a gradually diminishing scale of loss, $1^{\circ}$ 
for the first 100 , and so on until above three miles and a half it takes a thousand feet to lose the required degree of heat,- so geologists, instead of getting even a regular correspondence of $1^{\circ} \mathrm{Fahr}$. loss for every 63 feet of depth, find a gradual divergence in the ratio of vertical depth to loss of heat, and at one mile down have to go more feet to get it. And let it not be forgotten that these results have been given us by men who are pledged to the opposite view, who would rather not have known these truths, and perhaps would have hid them if they could. It is possible, then, that other causes than internal heat may have caused a former higher temperature of the globe. But more of this anon. Suppose now the other case-that the average temperature of the whole earth was $15^{\circ}$ less than it is now. What would be the result? Glaciers in Wales aud Scotland again as once there were befure; ice-floes in the valley of the Thames and on the Norfolk shores driving up the beds of sand and mud into contorted strata, such as we have in the Mundesley cliffs; and icebergs dropping -if the ocean-currents flowed on as once they did-boulders of scandinarian and other foreign rocks on the midland counties and the northern regions covered by the Glacial drift.

Miller has shown the beat of the sun to be not more than $14,580^{\circ}$ Fahr., - the heat of the oxy-bydrogen flame,-and probably it is not much less. Now the surface of the sun is given as 12,500 greater than the earth's, and, therefore, taking the earth's surfice as unity, we have the proportion of 12,500 to $1 . *$ If, therefore, assuming for convenience the temperature of the sun as $12,500^{\circ}$ (instead of $14,580^{\circ}$ Fahr.), we suppose our earth to fall into the sun, without iguiting on its external side, the total amount of heat radiated from his surface would evidently be $12,499^{\circ}$, or reduced by the size of the earth by one unit of beat, giving the surface the equivalent of one degree of heat.

But as the sun presents only one side to us, a loss of radiation of heat to the extent of two degrees would take place on the side of the sun to which the non-radiant earth was attached. As the sun however rotates on its axis in 25 days, every alternate fortnight or thereabouts the total temperature of the solar rays would be $2^{\circ} \mathrm{Fahr}$. less

* Considerable confusion of ideas and a want of logic will be attributed to me iu these articles if it be not distinctly borne in mind that $I$ adopt popular ideas and popular phraseology only for the moment, and that it is not intended to work these speculations juto any definite theory. If any definite conclusions be arrived at, they will be given as corollaries to these speculations, and not embodied in them. For example, we speak now upon the dictum that the volume of the sun is $1,400,000$ greater than the earth, its mass being as 354,936 to $l$, and its diameter as 882,000 to 8000 , or $111 \frac{1}{2}$ times greater than the earth. This gives the sun a mean density four times less than the earth,-a point we shall presently discuss, as it is very qucstionable if we ought to take the visible face of the sun, and his apparent size, in determining his density, because heated to the extent of nearly 15,000 degrees, and having, as astronomers declase, an exterior luminous photosphere; and, as Kichhof and Bunsen have shown, a still extcrior atmosphere of luninous incandescent metallic vapour. The light-exhausted internal uucleusof burnt-out and probably solid material of the central core of our luminary is what we ouglat to coussider as the actual globe of the sun, and which is what we should properly estimate for his mass and density, at any rate for purposes of comparison with our earth. 
than in the intervening periods. Now Tyndall speaks of the earth

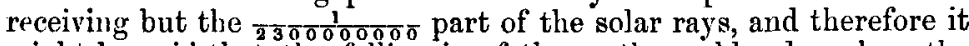
might be said that the falling in of the earth would only reduce the temperature of the earth by that part of a degree; but, on the other hand, we should have to consider what influence such an event would produce if the point of collision and obscuration was in a direct line with the earth. In such a case the direct light- and heat-rays would be shut off, and although compensated for in a great degree by the conrergence of the surrounding rays in the great flood of light coming away from the sun, a considerable effect might be produced on the temperature of the earth. Of what effect might be produced we have perhaps some examples in the actual effects produced by sun-spots. Single spots often appear of dimensions equal to and exceeding that of our earth, and periodically we have numerous congeries of spots of sufficient importance to produce disturbances at any rate of the magnetical conditions of our globe if not indeed to produce any distinctly perceptible diminution of temperature. That the latter effect might not be readily determinable in the converging or fluctuating states by our atmosphere is by no means surprising; but it should be borne in mind that A rago and other astronomers have asserted and attempted to prove that the maximum periods of sun-spots are regular decades of colder years. Such minute changes as those produced by these minor differences in the amount of materials in actual conflagration would have had little effect on the general climatal temperature of our earth, but if a difference, no matter how small, could in this or any other way be proved, it would be a basis for real conclusions on the subject. There are, however, five other ways in which the solar rays might affect the general climatal conditions of the earth. 1 . The mass of the sun being larger or smaller would radiate more or less heat accordingly. 2. There might be maximum and minimum periods of conflagratiun. 3. The extent of the earth's atmosphere might influence climatal condition by the conversion by friction of the light rays into heat, just as light rays falling on a black surface are arrested, annihilated, converted into heat, which they are, and on the same principle that a falling bullet striking the ground has its velocity or motion changed into an equivalent of heat. 4. A former higher and lower rate of rotation of our own globe would have important effects upon the climatal conditions and on the vegetation and life of our planet. 5. Variations in the dimensions of the orbit of the earth.

(To be continued.)

\section{ON CHELONIAN SCUTES FROM THE STONESFIELD} SLATE.

By C. Carter Blake, Esq.

In the British Museum there are several specimens of "papilionaceous" flattened bodies exhibiting six or more concentric lines ra- 